\title{
Effect of Fall Application of Fungal Antagonists on Spring Ascospore Production of the Apple Scab Pathogen, Venturia inaequalis
}

\author{
Odile Carisse, Vincent Philion, Daniel Rolland, and Julie Bernier
}

Agriculture and Agri-Food Canada, Horticultural Research and Development Centre, 430 Gouin Blvd., Saint-Jean-sur-Richelieu, Québec, Canada, J3B 3E6.

Accepted for publication 22 September 1999.

\begin{abstract}
Carisse, O., Philion, V., Rolland, D., and Bernier, J. 2000. Effect of fall application of fungal antagonists on spring ascospore production of the apple scab pathogen, Venturia inaequalis. Phytopathology 90:31-37.

The influences of Microsphaeropsis sp., M. arundinis, Ophiostoma sp., Diplodia sp., and Trichoderma sp., all antagonists of Venturia inaequalis, on ascospore production were evaluated under natural conditions and compared with urea and Athelia bombacina, a known antagonist. In the autumn, the fungi were applied to leaf disks artificially inoculated with $V$. inaequalis and to scabbed apple (Malus domestica) leaves incubated under controlled and natural conditions. In addition, large-scale trials were conducted with Microsphaeropsis sp. applied either as a foliar postharvest spray or as a ground application at $90 \%$ leaf fall. All fungal isolates, except Ophiostoma sp., were recovered from the leaf material that overwintered in the orchard. All treatments, except those with Ophiostoma sp.,
\end{abstract}

ABSTRACT

Apple scab, caused by the fungal pathogen Venturia inaequalis (Cooke) G. Wint., is considered to be the single most important disease of apples (Malus domestica Borkh.) in several production areas (28). Failure to control apple scab not only results in severe yield losses but also greatly reduces fruit market value. Currently, the strategy for apple scab control relies on multiple applications of fungicides $(18,30)$. These sprays represent an appreciable cost to growers. Also, there are concerns about the development of resistance to fungicides $(7,11,42)$.

Most research on apple scab has been focused on the control of primary infections and has resulted in spray schedules that essentially are based upon weather conditions that influence ascospore maturation (20) and infection (29), regardless of the inoculum potential. MacHardy et al. (30) showed that it is possible to delay the first fungicide applications up to the pink stage, when the inoculum potential is very low. The relation between the reduction of primary inoculum and scab severity has been clearly demonstrated by several authors $(1,9,20,25,35)$. In cold temperate regions, $V$. inaequalis overwinters as immature pseudothecia in fallen apple leaves, and the ascospores produced in the spring are considered to be the principle source of primary inoculum.

Many attempts have been made to reduce the overwintering inoculum of $V$. inaequalis, including mechanical removal or destruction of the fallen leaves $(27,32,44)$. The effect of various chemicals, including fungicides (benomyl, thiophanate-methyl, and carbendazime) and other chemicals (dinitro-o-cresol [DNOC], mercury,

Corresponding author: O. Carisse; E-mail address: carisseo@em.agr.ca

Publication no. P-1999-1118-01R

(C) 2000 Department of Agriculture and Agri-Food Canada, Government of Canada resulted in a significant reduction in $V$. inaequalis ascospore production on the leaf disks incubated under controlled conditions or in the orchard. In 1997, leaves with apple scab lesions treated with urea or Microsphaeropsis sp. produced significantly fewer ascospores of $V$. inaequalis than did nontreated leaves, with a reduction of 73.0 and $76.3 \%$, respectively. In 1998, leaves treated with Microsphaeropsis sp., urea, Trichoderma sp., A. bombacina, and $M$. arundinis reduced ascospore production by $84.3,96.6$, 75.2 , 96.6, and $52.2 \%$, respectively. Based on all tests combined, the most efficient isolate was Microsphaeropsis sp. Postharvest applications of Microsphaeropsis sp. reduced the total amount of airborne ascospores trapped by 70.7 and $79.8 \%$ as compared with the nontreated plots in 1997 and 1998, respectively. Microsphaeropsis sp. provided a significant and consistent reduction in ascospore production in all tests.

Additional keywords: apple scab management.

and lead arsenites) and urea $(8,9,17,25,26)$ were investigated. Most of these chemicals have shown good efficacy, but their use pose several problems such as environmental concerns, possible detrimental effects on tree growth, phytotoxicity, and potential to enhance resistance in the $V$. inaequalis populations.

The first occurrence in the literature suggesting biological control against the saprophytic phase of $V$. inaequalis was by Simard et al. in 1957 (41). More recently, the possibility of using a fungal antagonist to reduce ascospore production has been investigated in vitro (23) and under natural conditions (12,24,31). From these studies, the fungus Athelia bombacina Pers. was identified as a potential biological control agent. However, complete pseudothecia inhibition was obtained in field trials only when very high antagonist inoculum doses were used (21). When a lower rate was used, pseudothecial inhibition was reduced by only 60 to $70 \%$ (31).

Over 300 species of fungi have been isolated from orchards of several apple-producing regions of Québec, Canada (5). Some of these fungal isolates were tested for the inhibition of pseudothecia and ascospore production using in vitro leaf disk assays (37). From this evaluation, five fungal isolates (Microsphaeropsis sp., M. arundinis, Ophiostoma sp., Diplodia sp., and Trichoderma sp.) were selected based on their capacity to inhibit ascospore production. Recently, Benyagoub et al. (4) studied the interaction between $\mathrm{Mi}$ crosphaeropsis sp. (strain $\mathrm{P} 130 \mathrm{~A}$ ) and V. inaequalis and showed that Microsphaeropsis sp. was able to penetrate the $V$. inaequalis cell wall, inducing reduced growth or cell death.

The objective of this study was to evaluate the potential of the five fungal isolates to reduce the inoculum production of $V$. inaequalis under orchard conditions and to compare them with $A$. bombacina and urea, both known to inhibit pseudothecial production. Another objective was to evaluate the potential of Microsphaeropsis sp. to reduce airborne ascospore production. 


\section{MATERIALS AND METHODS}

Antagonist isolates and pathogen. Fungal antagonists were isolated from apple leaf litter in abandoned orchards of Quebec, Canada (5). Isolates P130A, previously identified as Coniothyrium sp., and P176A (6J-2), previously identified as Phoma sp., were reidentified as Microsphaeropsis sp. and M. arundinis, respectively. Isolate P11A (1H22) was identified as Trichoderma sp., isolate P164A as Ophiostoma sp., and isolate P138A as Diplodia sp. J. Andrews from the University of Wisconsin, Madison, kindly provided the culture of A. bombacina. All fungal cultures were stored on potato dextrose agar (PDA) (Difco Laboratories, Detroit) slants under mineral oil or in sterilized soil maintained at $2^{\circ} \mathrm{C}$. Prior to inoculations, the fungal antagonists were cultured on PDA. When each fungus had covered at least two-thirds of the surface of a 9-cm petri dish, it was stored at $2{ }^{\circ} \mathrm{C}$ for a maximum of 2 weeks until the day of inoculation. Mycelial slurries were prepared by homogenizing the fungal cultures in sterile distilled water at a ratio of $60 \mathrm{ml}$ of water for each petri dish with a Stomaker laboratory blender (Seward Medical, London). For all inoculum preparations, the final concentration ranged from 1.87 to $3.56 \times 10^{4}, 1.78$ to $3.41 \times 10^{4}$, 2.28 to $4.78 \times 10^{4}, 7.84$ to $9.86 \times 10^{3}, 1.37$ to $2.47 \times 10^{4}$, and 1.58 to $2.77 \times 10^{4} \mathrm{CFU} / \mathrm{ml}$ for Microsphaeropsis sp., M. arundinis, Trichoderma sp., Ophiostoma sp., Diplodia sp., and A. bombacina, respectively. Inoculum of $V$. inaequalis was prepared by culturing seven isolates (1An1.3, 9A1.1, 15A1.1, 18b2.2, 4b1.1, 26a3.3, and $15 \mathrm{~d} 2.1)$ obtained from our collection. These were grown on PDA at $15^{\circ} \mathrm{C}$ for at least 1 month. On the day of inoculation, one plate of each $V$. inaequalis isolate was inserted into a sterile plastic bag to which $100 \mathrm{ml}$ of distilled water was added. The contents of the bags were then homogenized as described for the fungal antagonists. The final concentration of the preparations ranged from 1.26 to $1.97 \times 10^{6} \mathrm{CFU} / \mathrm{ml}$.

Experiments with artificially inoculated leaf disks. The objective of the experiment was to determine the potential of the fungal antagonists to reduce ascospore production when applied under optimal conditions and to compare their efficacy under controlled and orchard conditions. Leaf disks of $2.7 \mathrm{~cm}$ in diameter were cut from apple leaves (cv. McIntosh) and sterilized by irradiation (10 h for a total of $40 \mathrm{kGy}$ ). In early October 1996 and 1997, leaf disks were inoculated with $50 \mu \mathrm{l}$ of a mycelial suspension of a mixture of $V$. inaequalis isolates and placed in 500-ml glass jars as described by Philion et al. (37). The leaf disks were maintained at room temperature for 3 weeks to allow $V$. inaequalis to colonize most of the disk surface. Each disk was then inoculated with the fungal antagonists at a rate of $50 \mu \mathrm{l}$ of mycelial slurry per leaf disk, 224 disks per treatment. After an incubation of 2 weeks at room temperature, a portion of the leaf disks (64 leaf disks) was incubated under controlled conditions in glass jars (four leaf disks per jar, 16 jars per treatment) as described by Philion et al. (37). The other leaf disks (160 disks) were incubated under orchard conditions in nylon mesh bags $(18 \times 40 \mathrm{~cm})$ fixed to the ground. In early spring, the bags were shielded from the rain with wooden covers to avoid ascospore ejection. The experiment was conducted twice as a completely randomized design with eight treatments (six fungal isolates, urea, and a control with only $V$. inaequalis) and eight sampling units (bags of 20 disks). The 5\% urea solution was applied at a rate of $1 \mathrm{ml}$ per leaf $(46 \% \mathrm{~N}, 5 \mathrm{~g} / 100 \mathrm{ml}$ of water) as described by Sutton (43).

Experiments with naturally infected leaves. The objective of this experiment was to evaluate and compare the efficacy of the fungal antagonists under natural conditions, including microbial competition. In the beginning of October 1996 and 1997, apple leaves (Malus domestic cv. McIntosh) infected with $V$. inaequalis were collected in an experimental orchard with a high level of scab. To reduce the variation among sampling units, only leaves showing between five and eight typical scab lesions were selected. The leaves were stored at $2^{\circ} \mathrm{C}$ in paper bags until processed. On 25 October
1996 and 23 October 1997, the scabbed leaves were inoculated with the fungal antagonists at a rate of $1 \mathrm{ml}$ of mycelial slurry per leaf. The leaves were then overwintered in nylon mesh bags (50 leaves per bag) fixed to the orchard floor. The experiment was conducted twice as a completely randomized design with eight treatments (six fungal isolates, urea, and a control with only $V$. inaequalis) and nine repetitions. All field trials were conducted at the Agriculture and Agri-Food Canada Experimental Farm at Frelighsburg, Québec, Canada.

Recovery of fungal antagonists. Colonization of the leaf disks by the fungal isolates was evaluated based on visual observations and reisolation. For each isolate, a portion of the leaf disks (32 incubated in vitro and 64 incubated in the orchard) was placed on petri dishes containing water agar amended with $100 \mathrm{mg}$ of tetracycline (Sigma Chemical Co., St. Louis) per liter. The plates with leaf disks were kept at room temperature and observed every 3 days for the presence of fungal structures for a period of 1 to 6 weeks. The same procedure was followed for the naturally infected leaves, except that 45 whole leaves were used instead of leaf disks. Preliminary tests showed that surface sterilization was not necessary and could, in fact, inhibit the growth of some of the fungi tested. Consequently, leaf disks or leaves were not surface-sterilized. Trichoderma sp. was identified based on spore morphology and typical pigmentation; Microsphaeropsis sp. and M. arundinis (isolates P130A and P176A) were identified based on presence of pycnidia and spore morphology (pale brown, aseptate, smooth, thin-walled, guttulate, cylindrical, and $5 \mu \times 2$ to $2.5 \mu$ ). A. bombacina was identified based on growth habit as described by Heye and Andrews (24). Ophiostoma sp. was identified based on shape of the mycelial aggregates, and Diplodia sp. was identified based on brown pigmentation of mycelium, presence of brown ostiolate pycnidia, and brown, thick-walled, two-celled pycnidiospores. When presence of the fungus was noted, it was isolated and cultured on PDA. Colonization was recorded as the proportion of the leaf disks or leaves from which the isolate was reisolated.

Field experiments with Microsphaeropsis sp. The objective of this experiment was to evaluate the potential of Microsphaeropsis sp. isolate P130A, to reduce the airborne ascospore concentration, and to compare the efficiency of a postharvest, preleaf fall tree application at about $10 \%$ leaf fall with a ground application at $90 \%$ leaf fall. The experiment was conducted during two seasons, 1996-1997 and 1997-1998, at the Agriculture Canada Experimental Farm in Frelighsburg, Québec, Canada. The experiment was conducted in a mature orchard of 0.41 ha planted with cvs. McIntosh (58\%) and Lobo (42\%). The dwarf trees grafted on M26 rootstock were planted at a distance of $5 \times 2.5 \mathrm{~m}$. Because of expected variations in scab levels among the plots, the potential ascospore dose (PAD) was measured in each plot, based on a late fall scab assessment, following the method described by MacHardy et al. (30). In each plot of 0.14 ha (five rows of 22 trees), 20 shoots were evaluated on 10 'McIntosh' trees chosen randomly in the subplot, for a total of 200 shoots. Scab incidence was assessed within 2 weeks after harvest by counting the number of infected leaves per shoot and expressed as percent scabbed leaves.

To produce large quantities of spores, Microsphaeropsis sp. mycelium was first produced in liquid cultures. Erlenmeyer flasks of 250-ml capacity containing $100 \mathrm{ml}$ of sterilized malt extract (Sigma Chemical Co.) were inoculated with a 6-mm mycelial plug cut from the edge a 15-day-old culture of Microsphaeropsis sp. The flasks were maintained at room temperature in a rotary $(240 \mathrm{rpm})$ shaker (Orbit Eviron-Shaker; Lab-Lie, Melrose Park, IL) for 15 days. Five hundred grams of barley grains was placed in 900-ml glass jars and soaked in distilled water for $24 \mathrm{~h}$. The excess water was drained and the barley was autoclaved twice for $15 \mathrm{~min}$ at $121^{\circ} \mathrm{C}$ and $140 \mathrm{KPa}$. After cooling, each jar was inoculated with $500 \mu \mathrm{l}$ of the liquid culture. The jars were then maintained at room temperature for 3 to 4 weeks and shaken every day for approximately $30 \mathrm{~s}$. On the day of application, inoculum was prepared by mixing 
two jars containing the barley grains covered with mature pycnidia with 2.5 liters of distilled water into 3-liter beakers. The mixture was agitated for 20 to $30 \mathrm{~min}$ and then filtered through two layers of cheesecloth. When the volume reached approximately 15 liters, the concentration was adjusted to $6.75 \times 10^{9}$ conidia per $\mathrm{ml}$ in order to obtain $4.5 \times 10^{5}$ conidia per $\mathrm{ml}$ once diluted in the tank mix.

The spore suspension was applied either to the tree canopy at less than $10 \%$ leaf fall or as a ground application at $90 \%$ leaf fall at a rate of 1,125 liters/ha, corresponding to approximately 1.2 liters per tree. The tree canopy application was done on 11 and 17 October in 1996 and 1998, respectively, and the ground application on 12 and 26 November in 1996 and 1998, respectively. The spore suspension was applied using a gasoline-powered Solo backpack sprayer (model 422; Solo, Sindelfingen, Germany) and a handheld gun mounted with a single nozzle with an $80^{\circ}$ flat spray tip operated at $620 \mathrm{KPa}$ with a flow rate of approximately 2.2 liters/ min. Five samples of 15 to $25 \mathrm{ml}$ of the tank mix were collected while spraying each plot. Samples were kept on ice until the evaluation of spore concentration and germination. Within $24 \mathrm{~h}$, the spore concentration was estimated using a hemacytometer. Spore germination was evaluated by pouring $1 \mu \mathrm{l}$ of spore suspension onto water agar plates and incubating them at room temperature. After $24 \mathrm{~h}, 100$ spores per plate were observed for germination. Spores were considered to have germinated when the germ tube was at least the length of the spore.

Quantification of ascospore production. Ascospore production on artificially inoculated leaf disks was evaluated when ascospores from nontreated leaf disks were mature as determined by squash mounts (19). To evaluate ascospore production per leaf disk, two leaf disks were placed in a 50-ml Falcon test tube (Fisher Scientific, Montreal, Canada) (16 tubes per treatments) with $20 \mathrm{ml}$ of distilled water and exposed to air turbulence for $1 \mathrm{~h}$ (37). A few drops of Lugol's iodine solution were added to each ascospore suspension to stop germination, and the contents of the tubes were centrifuged at 2,000 $\times g$ for $10 \mathrm{~min}$ (Accuspin FR, Beckman, CA). The liquid was carefully drawn out of the tubes so that the pellet and surrounding liquid were not disturbed in order to obtain $5 \mathrm{ml}$ of ascospore suspension. Ascospore concentrations were determined using a hemacytometer and ascospore productivity reported for each treatment as the ascospore production per square centimeter of leaf tissue.

Ascospore production on naturally infected leaves was evaluated during the entire ascospore ejection period, from late April to the end of June. One leaf was selected arbitrarily from each sampling unit (nylon bag), for a total of nine leaves per treatment, and placed on the wire bottom of a wooden spore trap (14), the top surface facing up. Microscope slides, previously coated with petroleum jelly, were placed above the leaves at a height of $0.5 \mathrm{~cm}$. After each rain, all the slides were collected and replaced by new ones, and the slides were stored at $10^{\circ} \mathrm{C}$ until examination. The number of ascospores present on $40 \%$ of the slide surface was counted under microscope at a magnification of $\times 250$, and ascospore production was expressed on a per slide basis.

The effect of Microsphaeropsis sp. on ascospore production in the orchard was evaluated by measuring the airborne concentration of ascospores of $V$. inaequalis during each period conducive to both ascospore ejection and infection. Homemade volumetric spore samplers (rotary impaction type) similar to the Rotorod device were used for this purpose (36). The onset of rain or dew, which triggers ascospore liberation, was determined using electrical grid leaf wetness sensors installed at the ground level. The signal was transmitted to a datalogger (CR-10; Campbell Scientific Inc., Logan, UT) that in turn activated the spore samplers. Two spore samplers were installed in each of the three plots and ran consecutively for $4 \mathrm{~h}$, until the end of the rain, or for a maximum of $8 \mathrm{~h}$. Since ascospore infection is not possible once the leaves are dry, the end of the rain event was determined with the drying of the wetness sensors installed within the tree canopy. The sampling heads were set at $40 \mathrm{~cm}$ above the ground and shielded from the rain with a plastic cover $10 \mathrm{~cm}$ above the heads. For each rain conducive to infection, the number of ascospores on the entire surface of the exposed area of the rods was counted and ascospore concentration was expressed as the number of ascospores per cubic meter of air sampled. Airborne ascospores were monitored from 11 May to 20 June 1997 and from 24 April to 11 June 1998, for a total of ten and nine rain events in 1997 and 1998, respectively.

Statistical analysis. Tests of homogeneity of variances ( $F$ tests) were conducted to determine if data from the two experimental runs could be pooled and to ensure the underlying assumptions of the statistical models. Analysis of variance was used to test the effect of fungal isolates on total ascospore production; multiple comparison tests (least significant difference). to detect significant differences among means; and orthogonal comparison, to compare different levels of treatments with the control ( $V$. inaequalis alone) at the 0.05 confidence level. Repeated measures analysis was used to test the effect of fungal isolates on ascospore production for each sampling date, because data were collected over time from the same leaves and, therefore, were not independent (Manova procedure). Analysis of variance and orthogonal comparisons were also used to test the effect of Microsphaeropsis sp. (strain P130A) on airborne ascospore production and to compare the two application types (tree versus ground). Statistical analysis was conducted using the SAS software program (SAS Institute, Inc., Cary, NC).

\section{RESULTS}

Recovery of fungal antagonists. All fungal isolates were recovered in high proportions (84 to $100 \%$ ) from the leaf disks incubated in vitro. However, colonization was lower on the leaf disks and detached leaves overwintered in the orchard (Fig. 1). Ophiostoma sp. was recovered from less that $10 \%$ of the samples when leaf disks or entire leaves were overwintered in the orchard. In contrast, Trichoderma sp. was recovered from almost all samples (86 to $90 \%$ ). The other fungal isolates were recovered in about two-thirds of the samples.

Experiments with artificially inoculated leaf disks. Based on homogeneity of variance, the data from the two experimental, runs were pooled. When leaf disks was not treated, an average of $1.28 \times$ $10^{3}$ and $1.59 \times 10^{3}$ ascospores per $\mathrm{cm}^{2}$ were obtained from leaf disks incubated under controlled conditions and overwintered in the orchard, respectively (Fig. 2A and B). On leaf disks incubated

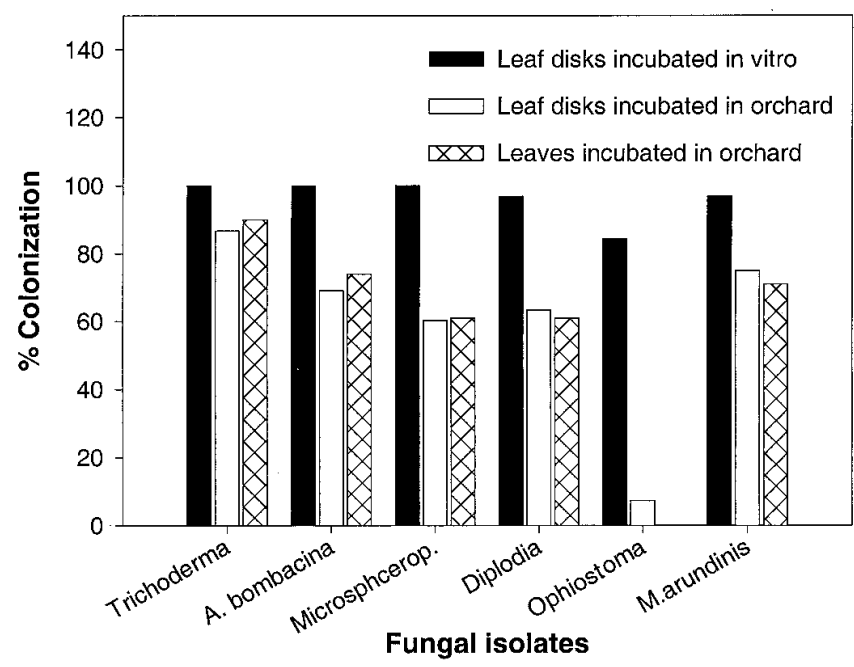

Fig. 1. Recovery of the fungal isolates inoculated on apple leaf disks incubated under controlled conditions, on leaf disks overwintered in the orchard, and from detached apple leaves overwintered in the orchard. The percentage of recovery was calculated from samples of 32 leaf disks incubated under controlled conditions, 64 leaf disks overwintered in the orchard, and 45 apple leaves overwintered in the orchard. 
under controlled conditions, significant ascospore reduction $(P \leq$ 0.0001) was observed for all treatments except those with Ophiostoma sp. (Fig. 2A). The trend was similar for leaf disks incubated in the orchard, with significant ascospore inhibition $(P \leq 0.0001)$ for all treatments except those with Ophiostoma sp. (Fig. 2B). On leaf disks incubated under controlled conditions, the greatest ascospore inhibition was observed on leaf disks treated with $A$. bombacina, followed by Microsphaeropsis sp., Trichoderma sp., urea, M. arundinis, and Diplodia sp., reducing ascospore production by $96,94,89,85,77$, and 65\%, respectively. On leaf disks overwintered in the orchard, the same treatments resulted in an ascospore reduction of $80,96,94,89,81$, and $57 \%$, respectively.

Experiment with naturally infected leaves. On naturally infected apple leaves, more ascospores were observed on the control during the spring of 1998 than of 1997, with a seasonal total of $2.16 \times 10^{4}$ and $1.07 \times 10^{4}$ ascospores per leaf, respectively (Fig. 3A and B). In both years, Diplodia sp. failed to inhibit ascospore production. In 1997, leaves treated with urea or Microsphaeropsis sp. produced significantly fewer ascospores than did nontreated leaves $(P=0.0109$ and 0.0254 , respectively), with a reduction of 73.0 and $76.3 \%$, respectively (Fig. 3A). The other treatments did not result in a significant ascospore reduction (Fig. 3A). In 1998, leaves treated with Microsphaeropsis sp., urea, Trichoderma sp., A. bombacina, and Ophiostoma sp. produced significantly fewer ascospores $(P=0.0048,0.0013,0.0116,0.0013$, and 0.0323 , respectively), with a percent reduction of $84.3,96.6,75.2,96.6$, and $52.2 \%$, respectively (Fig. 3B). For the 2 years of the experiment, the pattern of ascospore ejection over time was similar on treated
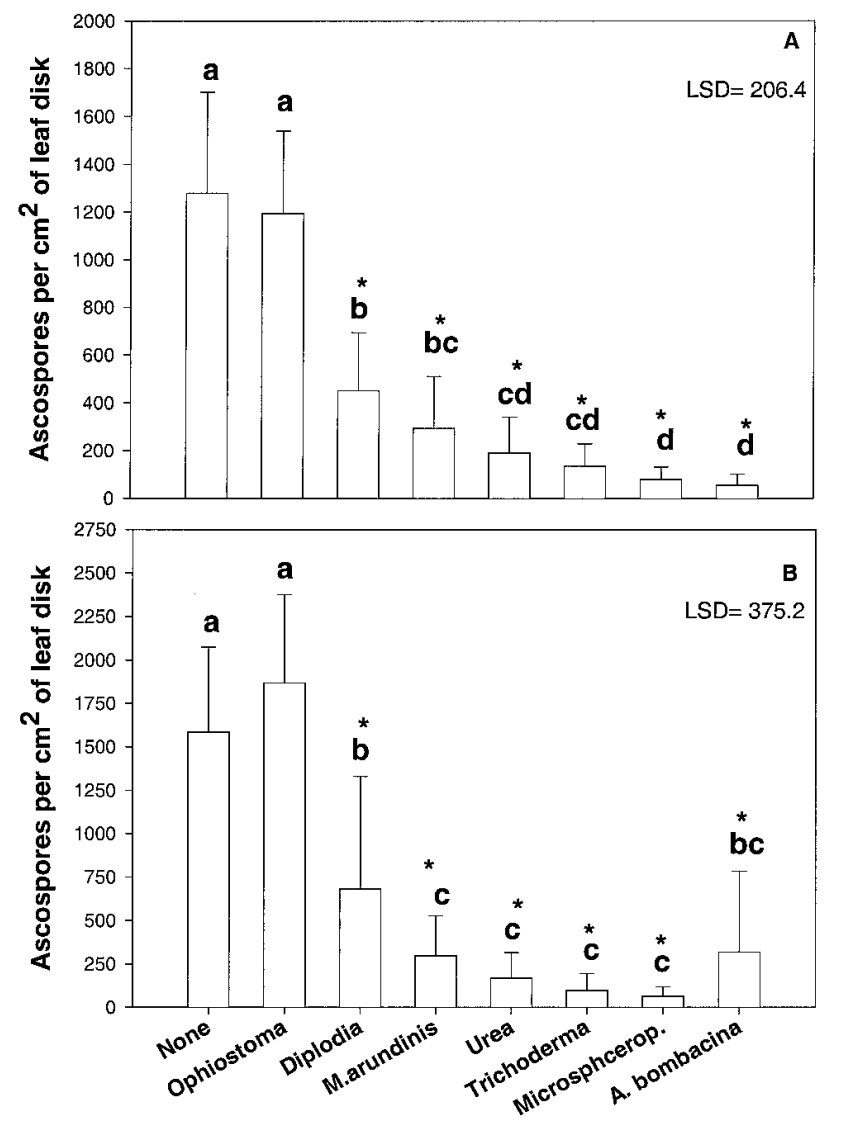

Treatments

Fig. 2. Ascospore production from leaf disks incubated under A, controlled conditions and $\mathbf{B}$, orchard conditions. Bars with the same letters are not significantly different according to the least significant difference test (LSD, at the 0.05 level of confidence). Bars with * are significantly different from the control (nontreated leaves) based on orthogonal comparison $(P=0.05)$. Data from 1997 and 1998 were pooled. and nontreated leaves, with maximum ejection occurring on 23 May 1997 and 5 May 1998 (Fig. 4A and B). Repeated measures analysis revealed that there was a significant effect of fungal isolates $(P<$ $0.0001)$ and time $(P<0.0001)$ and that the effect of fungal isolates on ascospore production varied over time $(P=0.05)$. In general, the effect of fungal isolates on ascospore production was not significant when the amount of ascospores ejected was low. Overall, for all tests, the best four treatments in terms of reduction of ascospore production were those with Microsphaeropsis sp., urea, A. bombacina, and Trichoderma sp.

Field experiment with Microsphaeropsis sp. Percent germination of the Microsphaeropsis sp. spore suspension was high in all samples, ranging from 88 to $98 \%$. In the fall of 1996, scab incidence in orchard plots prior to the treatments with Microsphaeropsis sp. was $2.56,4.08$, and $3.14 \%$ for the control, the canopy, and the ground applications, respectively. In 1997, for the same treatments, disease incidence was 9.0, 23.0, and 8.0\%, respectively. Both ground and canopy application of Microsphaeropsis sp. significantly $(P=0.0006)$ reduced airborne ascospore concentration (Fig. 5). The application of Microsphaeropsis sp. to the tree canopy at less than $10 \%$ leaf fall resulted in a reduction in the total amount of ascospores trapped of 70.7 and $79.8 \%$ as compared with that of the untreated plot in 1997 and 1998, respectively (Fig. 5A and B). The ground application, at $90 \%$ leaf fall, resulted in a reduction in airborne ascospore concentration of 60.1 and $62.6 \%$ in 1997 and 1998, respectively. In both years, significantly fewer ascospores $(P=0.0003)$ were trapped when Microsphaeropsis $\mathrm{sp}$. was applied on leaves still attached to the trees compared

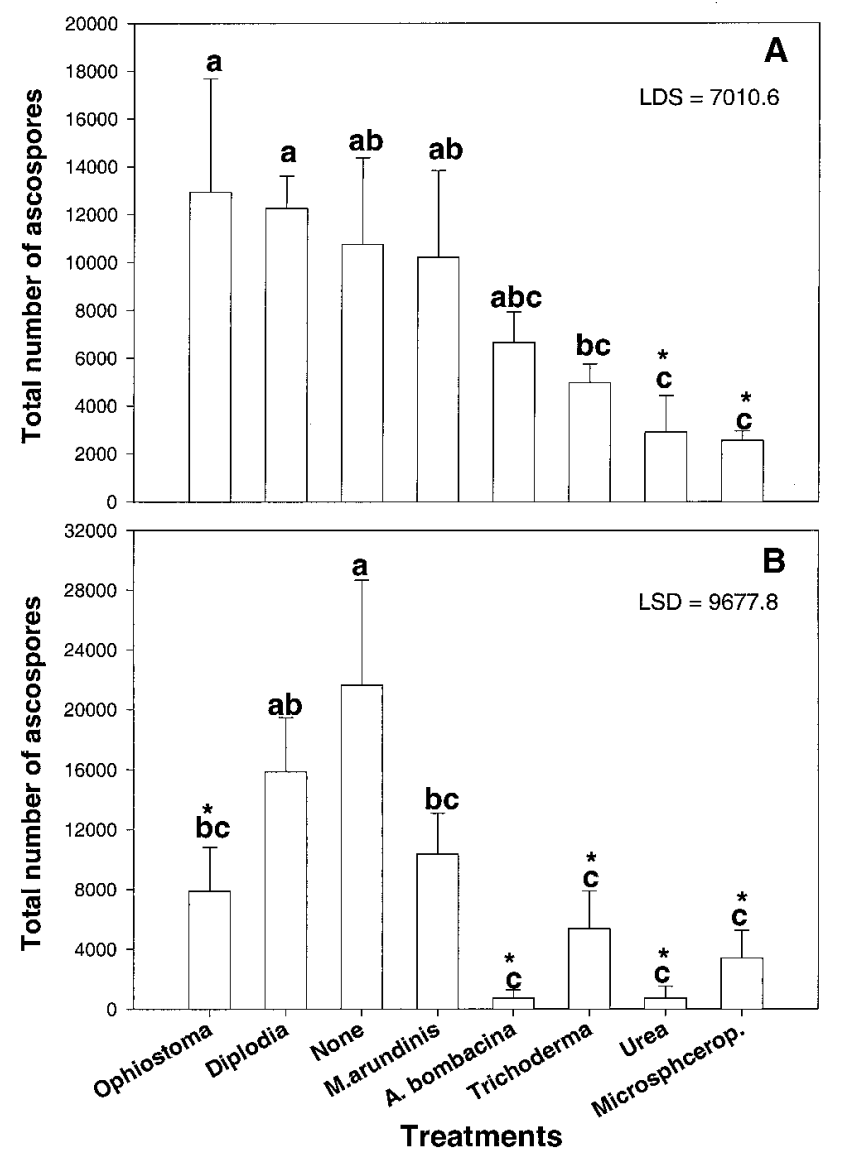

Fig. 3. Total ascospore production during the spring of A, 1997 and B, 1998 from detached scabbed leaves treated with the fungal antagonists and urea. Bars with the same letters are not significantly different according to the least significant difference test (LSD, at the 0.05 level of confidence). Bars with * are significantly different from the control (nontreated leaves) based on orthogonal comparison $(P=0.05)$. 
with that on fallen leaves. The canopy application was done in a plot with a ascospore potential of 1.5 and 2.5 times higher than that in the control in 1997 and 1998, respectively, which was conservatively established in the plot with the lowest level of scab.

\section{DISCUSSION}

Most of the fungal antagonists were recovered from the leaf material that overwintered in the orchard. Ophiostoma sp. was the exception and was recovered from less than $10 \%$ of the samples, which can be explained by the slow growth rate of this isolate and its poor leaf colonization ability. With the exception of Ophiostoma sp., all antagonists and urea significantly reduced ascospore production on the leaf disks artificially inoculated with $V$. inaequalis. These results are in complete agreement with those obtained by Philion et al. (37), who selected these fungi based on a similar test. On the leaf disks, the fungal antagonist is in direct contact with $V$. inaequalis, which probably explains the high level of inhibition. The fungi had a similar effect on leaf disks incubated under controlled and orchard conditions. This indicates that microbial competition with other organisms may not play a major role in the interaction between the antagonists and $V$. inaequalis, except for A. bombacina. However, on the naturally infected apple leaves, the level of ascospore inhibition was lower for most of the fungal isolates. Scab on these leaves may have been more difficult to control than that on the artificially inoculated leaf disks, in part, because $V$. inaequalis was already established within leaves when the antagonists were applied, thus occupying a critical ecological niche partly shielding it from antagonism.

In a recent study by Ouimet et al. (34) on the effect of fungal antagonists on in vitro inhibition of vegetative growth of $V$. inae-
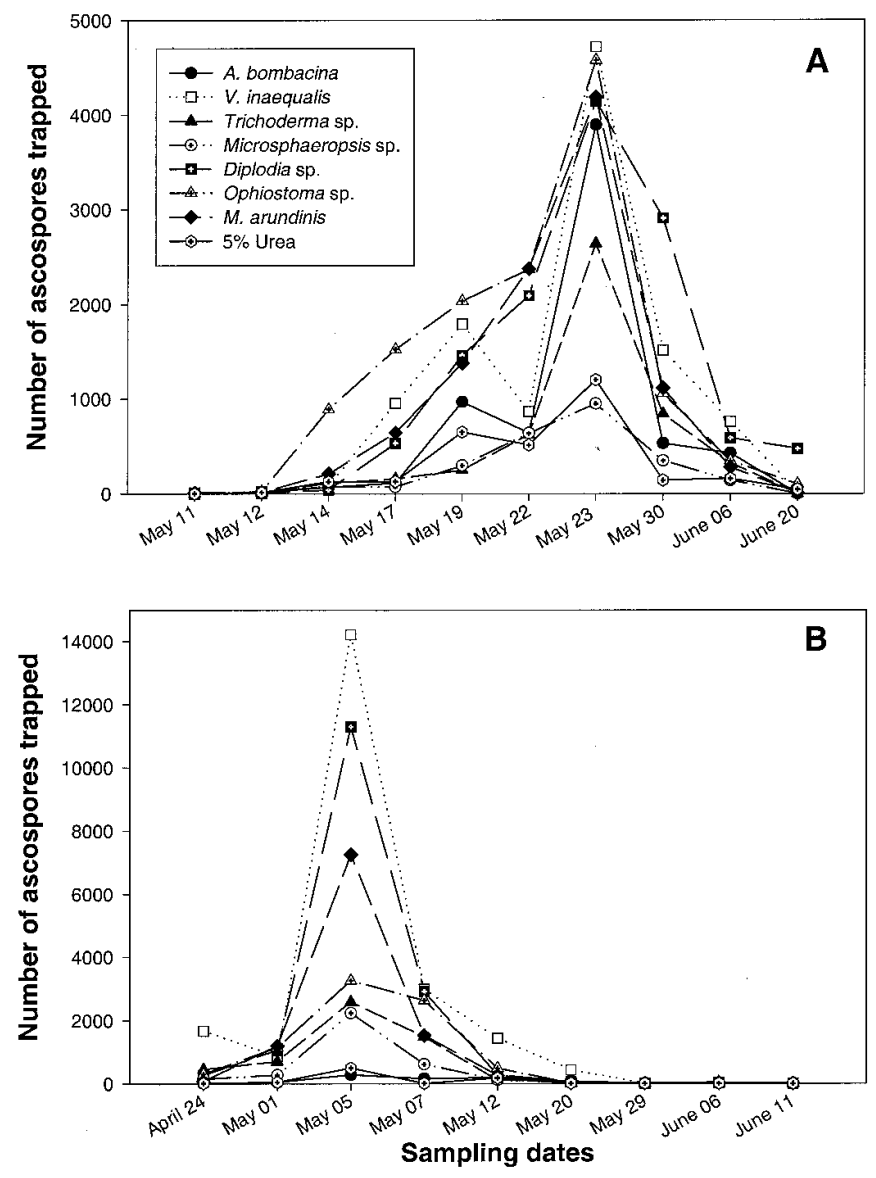

Fig. 4. Ascospore production from detached scabbed leaves treated in the fall with the fungal antagonists and urea. Ascospore production was measured for each rain in A, 1997 and B, 1998. qualis, the isolate of Ophiostoma sp. completely prevented mycelial growth regardless of the temperature, $\mathrm{pH}$, or light conditions. In the study by Philion et al. (37), it reduced ascospore production by $88.7 \%$ in one trial; however, in another trial, ascospore inhibition was only $8.2 \%$. In the current study, this isolate failed to inhibit ascospore production, with an average ascospore inhibition of $8.2 \%$ for all tests combined. A previous experiment (37) showed the potential of $M$. arundinis and Diplodia sp. for inhibiting ascospore production; but in our experiments, they did not provide a high and consistent level of inhibition, making them uninteresting for biological control.

In our study, the four best treatments were those with Trichoderma sp., A. bombacina, urea, and Microsphaeropsis sp., with an overall ascospore inhibition (all tests combined) of 83.7, 84.2, 87.7 , and $90.4 \%$, respectively. Our findings on the effect of $A$. bombacina are similar to those obtained by Heye and Andrews (24), Miedtke and Kennel (31), and Philion et al. (37). Heye and Andrews (24) observed a complete ascospore inhibition on leaf disks incubated in the laboratory and on intact leaves incubated in the orchard. However, they used a large quantity of $A$. bombacina inoculum equivalent to approximately five times the amount used in the current study. In their study, Miedtke and Kennel (31) used lower amounts of inoculum, approximately double what was used here, and observed a reduction in ascospore production of only 60 to $70 \%$. In our experiment, with relatively low amounts of inoculum, we observed an overall ascospore inhibition of $84.22 \%$, although Trichoderma sp. and Microsphaeropsis sp. were as good as $A$.
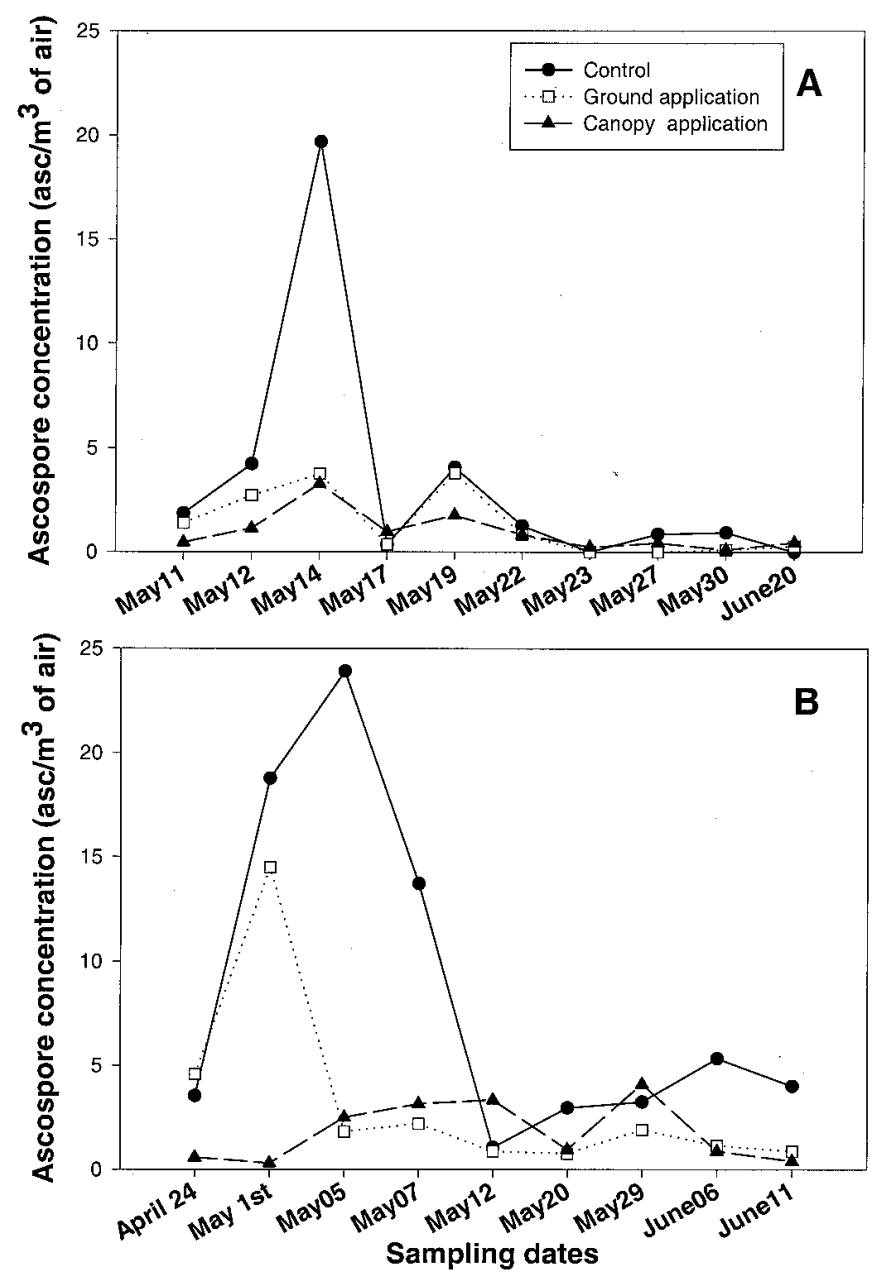

Fig. 5. Airborne ascospore concentration in orchard plots treated in the fall with the fungal antagonist Microsphaeropsis sp. applied as a foliar spray at $10 \%$ leaf fall or as a ground application at $90 \%$ leaf fall as compared with a nontreated plot. Airborne ascospore concentration production was measured for each rain in A, 1997 and B, 1998. 
bombacina in reducing ascospore production. Trichoderma sp. caused a reduction in ascospore production of 83.3 and $93.8 \%$ on leaf disks. On scabbed leaves, the reduction was only $68.1 \%$. These results are similar to those observed by Ciotola (12), who reported the failure of $T$. reesei to reduce ascospore production under natural conditions.

Urea provided a high and consistent ascospore inhibition varying from 85.0 to $89.2 \%$, depending on the experiment. The effect of autumn treatments with urea has been investigated by several authors $(9,15,17,21,22,33,38)$. In most of these studies, urea provided complete eradication of pseudothecia or ascospore production and its effect is well documented. The application of urea stimulates the growth of microorganisms (13), which increases microbial competition. Among the microorganisms, some are antagonistic of $V$. inaequalis $(22,38)$. Also, leaf softening induced by urea $(8,13,23)$ promotes leaf removal by decomposing microorganisms (13). The application of urea causes an increased leaf nitrogen content and, consequently, a nitrogen-carbon imbalance that inhibits pseudothecia $(13,23,38)$. Despite the obvious effect of urea application on ascospore production, very few experiments in large plots have been conducted. In such an experiment, Sutton (43) observed a reduction in relative ascospore dose of $74 \%$ following a spring urea application on leaf litter. However, the fall application of 5\% urea failed to significantly reduce ascospore production. The effect of urea application on winter hardening of the apple trees is unclear. Shim et al. (40) showed that, following a postharvest urea application, most of the $\mathrm{N}$ content was translocated from leaves to storage tissues during leaf senescence; however, they did not observe winter injuries for the 2 years of the experiment.

Microsphaeropsis sp. was consistent in its effect on the production of ascospores by $V$. inaequalis, with ascospore inhibition varying from 81 to $96 \%$ in all the tests conducted with detached leaves. These results are similar to those obtained by Philion et al. (37), who observed an in vitro ascospore reduction of 98.6 and $99.2 \%$. The effect of Microsphaeropsis sp. on ascospore reduction was higher on leaf disks (93.67 and $95.97 \%$ ) than on naturally infected apple leaves $(81.64 \%)$ and lowest when applied in large plots (75.27\% for the canopy application). This diminution in efficacy can probably be explained by the different levels of contact between Microsphaeropsis sp. and V. inaequalis and by the conditions for leaf colonization by Microsphaeropsis sp. On the leaf disks, 2 weeks of incubation at room temperature were allowed for colonization. On the scabbed leaves, the antagonists were exposed to weather conditions immediately after their application on leaves, which may have had an effect on the ability of the antagonist to become established on or in the leaves. The tests in orchard plots were even more severe. For the canopy application, Microsphaeropsis $\mathrm{sp}$. was exposed to adverse conditions due to the low level of humidity, fluctuating temperatures, and presence of wind. To our knowledge, it is the first evaluation of a microbial control agent for apple scab in large plots. This test was necessary because it is more similar to commercial conditions than to detached leaf tests. The mode of action of this isolate of Microsphaeropsis $\mathrm{sp}$. is not fully established. However, Benyagoub et al. (4) reported that the interaction between $V$. inaequalis and Microsphaeropsis sp. proceeds via mycoparasitism and involves both enzymatic activity and antibiosis. This is in contrast to a report by Andrews et al. (3), who suggested that microbial antagonism of the vegetative stage of $V$. inaequalis by $M$. olivacea operated through nutrient competition.

The isolate of Microsphaeropsis sp. tested in this study produces large quantities of spores, making it a good candidate for commercialization. However, the effect of Microsphaeropsis sp. on scab development remains to be established under commercial conditions. Regardless of how the ascospore reduction is achieved, it will not, by itself, solve the problem of apple scab. Much more work is needed to integrate biological control in scab management. Research on biological control of apple scab has been oriented toward interrupting the secondary cycles by preventing conidial infection $(10,16)$ or toward reducing primary inoculum by interfering with the overwintering of pseudothecia $(12,23,31,37)$. In general, biological control of primary and secondary infections using microorganisms either failed (6) or testing did not reach the field level (10). Chemical fungicides are generally efficient in controlling primary and secondary infections; consequently, biological control strategies aiming to control leaf infection have a limited commercial future. Since chemical fungicides should not be used in the fall because of detrimental environmental impact and spread of resistance, the reduction of the initial inoculum as a result of the application of a biological control agent can be part of integrated scab management. If the primary inoculum is substantially reduced, the fungicide program could be delayed (30) or ended earlier, resulting in fungicide savings. The ascospore threshold at which fungicide application is required remains to be established. Currently, the action threshold is determined by simply relating the PAD reduction to a theoretical delay in epidemic onset. Anagnostakis and Aylor (2) and Sanogo and Aylor (39) reported that the infection efficiency of ascospores was 5 to $14 \%$ on apple leaves and 6 to $21 \%$ on apple flower buds based on actual ascospore concentrations measured at the leaf level using microscope slides. Philion et al. (36) reported that leaf infection on potted trees occurred when more than 150 ascospores per spore trap were collected.

From the current study, it can be expected that Microsphaeropsis sp. could reduce overwintering inoculum by at least $75 \%$ and may serve as insurance for the elimination of these early season sprays. Nevertheless, results are encouraging if a similar effect could be obtained in a commercial orchard. For instance, by improving formulation and the application technique, we could envision a scab control program in which at least the first few fungicide applications could be avoided.

\section{LITERATURE CITED}

1. Adams, J. F. 1925. The spore discharge of the apple scab fungus in Delaware. Del. Agric. Exp. Stn. Bull. 140.

2. Anagnostakis, S. L., and Aylor, D. E. 1991. Efficiency of ascospores of Venturia inaequalis in producing scab lesions on apple leaves. Plant Dis. 75:918-920.

3. Andrews, J. H., Berbee, F. M., and Nordheim, E. V. 1983. Microbial antagonism to the imperfect stage of the apple scab pathogen, Venturia inaequalis. Phytopathology 73:228-234.

4. Benyagoub, M., Benhamou, N., and Carisse, O. 1998. Cytochemical investigation of the antagonistic interaction between a Microsphaeropsis sp. (isolate P130A) and Venturia inaequalis. Phytopathology 88:605-613.

5. Bernier, J., Carisse, O., and Paulitz, T. C. 1996. Fungal communities isolated from dead apple leaves from orchards in Quebec. Phytoprotection 77:129-134.

6. Boudreau, M. A., and Andrews, J. H. 1987. Factors influencing antagonism of Chaetomium globosum to Venturia inaequalis: A case study in failed biocontrol. Phytopathology 77:1470-1475.

7. Braun, P. G., and McRae, K. B. 1992. Composition of a population of Venturia inaequalis resistant to myclobutalanil. Can. J. Plant Pathol. 14: 215-220.

8. Burchill, R. T., and Cook, R. T. A. 1970. The interaction of urea and micro-organism in suppressing the development of perithecia of Venturia inaequalis (Cke) Wint. Pages 471-483 in: Ecology of Leaf Surface Micro-Organisms. T. F. Preece and C. H. Dickinson, eds. Academic Press, New York.

9. Burchill, R. T., and Hutton, K. E. 1965. The suppression of ascospore production to facilitate the control of apple scab (Venturia inaequalis (Cke) Wint.). Ann. Appl. Biol. 56:285-292.

10. Burr, T. J., Matteson, M. C., Smith, C. A., Corral-Garcia, M. R., and Huang, T.-C. 1996. Effectiveness of bacteria and yeast from apple orchards as biological control agents of apple scab. Biol. Control 6:151-157.

11. Carisse, O., and Pelletier, J. R. 1994. Sensitivity distribution of Venturia inaequalis to fenarimol in Québec apple orchards. Phytoprotection 75:35-43.

12. Ciotola, M. 1987. Influence du Trichoderma reesei et de l'urée sur le développement du Venturia inaequalis. M.Sc. thesis. University of Montreal, Montreal, Canada.

13. Cook, R. T. A. 1969. Studies on the overwintering of Venturia inaequalis (Cke.) Wint. Ph.D. dissertation. University of London, London. 
14. Coulombe, L. J. 1976. Répression de l'infection primaire de la tavelure sur du pommiers McIntosh par l'emploi de Captafol en dose massive. Phytoprotection 57:23-32.

15. Cross, J. E., Garrett, C. M. E., and Burchill, R. T. 1968. Changes in the microbial population of apple leaves associated with the inhibition of the perfect stage of Venturia inaequalis after urea treatment. Ann. Appl. Biol. 61:203-216.

16. Cullen, D., Berbee, F. M., and Andrews, J. H. 1984. Chaetomium globosum antagonizes the apple scab pathogen, Venturia inaequalis, under field conditions. Can. J. Bot. 62:1814-1818.

17. Darpoux, H., Lebrun, A., and Tullaye, B. 1975. Action de traitement sur la formation des périthèces et la production de l'inoculum primaire de Venturia inaequalis (Cooke) Wint. et de Venturia pirina Adher. Phytiatr.Phytopharm. Rev. Fr. Med. Pharm. Veg. 24:3-14.

18. Ellis, M. A. 1990. Disease management strategies for controlling apple scab. Pages 3-9 in: New Directions in Tree Fruit Pest Management. K. Williams, ed. Good Fruit Grower, Yakima, WA.

19. Gadoury, D. M., and MacHardy, W. E. 1982. Preparation and interpretation of squash mounts of pseudothecia Venturia inaequalis. Phytopathology 72:92-95.

20. Gadoury, D. M., and MacHardy, W. E. 1986. Forecasting ascospore dose of Venturia inaequalis in commercial apple orchards. Phytopathology 76:112-118.

21. Gupta, G. K. 1979. Role of on-season, post harvest and pre leaf fall sprays in the control of apple scab (Venturia inaequalis). Indian J. Mycol. Plant Pathol. 9:141-149.

22. Gupta, G. K., and Lele, V. C. 1980. Role of urea in suppression of ascigerous stage, and comparative in-vitro efficacy of fungicides against apple scab. Indian J. Agric. Sci. 50:167-173.

23. Heye, C. C. 1982. Biological control of the perfect stage of the apple scab pathogen, Venturia inaequalis (Cke) Wint. Ph.D. thesis. University of Wisconsin, Madison.

24. Heye, C. C., and Andrews, J. H. 1983. Antagonism of Athelia bombacina and Chaetomium globosum to the apple scab pathogen, Venturia inaequalis. Phytopathology 73:650-654.

25. Hirst, J. M., and Stedman, O. J. 1962. The epidemiology of apple scab (Venturia inaequalis (Cke) Wint). III. The supply of ascospores. Ann. Appl. Biol. 50:551-567.

26. Keitt, G. W., and Palmiter, D. H. 1937. Potentialities of eradicant fungicides for combating apple scab and some other plant diseases. J. Agric. Res. 55:397.

27. Keitt, G. W., and Wilson, E. E. 1927. A possible reorientation of aims and methods for apple scab control. Phytopathology 17:45.

28. MacHardy, W. E. 1996. Apple Scab Biology, Epidemiology, and Management. The American Phytopathological Society, St. Paul, MN.

29. MacHardy, W. E., and Gadoury, D. M. 1989. A revision of Mills's criteria for predicting apple scab infection periods. Phytopathology 79:304-310.

30. MacHardy, W. E., Gadoury, D. M., and Rosenberger, D. A. 1993. Delaying the onset of fungicide programs for the control of apple scab in orchards with low potential ascospore dose of Venturia inaequalis. Plant Dis. 77:372-375.

31. Miedtke, U., and Kennel, W. 1990. Athelia bombacina and Chaetomium globosum as antagonists of the perfect stage of the apple scab pathogen (Venturia inaequalis) under field conditions. J. Plant Dis. 97:24-32.

32. Mills, W. D. 1944. Efficient use of sulfur dusts and sprays during rain to control apple scab. Cornell Ext. Bull. 630.

33. Moller, W. J. 1981. Efficacy of autumn urea in reducing spring inoculum of apple scab. Calif. Plant Pathol. 52.

34. Ouimet, A., Carisse, O., and Neumann, P. 1997. Evaluation of fungal isolates for the inhibition of the vegetative growth of Venturia inaequalis. Can. J. Bot. 75:626-631.

35. Palmiter, D. H. 1946. Ground treatments as an aid in apple scab control. N.Y. Agric. Exp. Stn. Bull. 714.

36. Philion, V., Carisse, O., Garcin, A., and Vanesson, S. 1997. Monitoring airborne ascospore of Venturia inaequalis. IOBC/WPRS Bull. Vol. 20(9): 180-184.

37. Philion, V., Carisse, O., and Paulitz, T. 1997. In vitro evaluation of fungal isolates for their ability to influence leaf rheology, production of pseudothecia, and ascospores of Venturia inaequalis. Eur. J. Plant Pathol. 103:441-452.

38. Ross, R. G., and Burchill, R. T. 1968. Experiments using sterilized apple-leaf discs to study the mode of action of urea in suppressing perithecia of Venturia inaequalis (Cke) Wint. Ann. Appl. Biol. 62:289-296.

39. Sanogo, S., and Aylor, D. E. 1997. Infection efficiency of Venturia inaequalis ascospores as affected by apple flower bud developmental stage. Plant Dis. 81:661-663.

40. Shim, K. K., Titus, J. S., and Splittstoesser, W. E. 1972. The utilization of post-harvest urea sprays by senescing apple leaves. J. Am. Soc. Hortic. Sci. 97:592-596.

41. Simard, J., Pelletier, R. L., and Coulson, J. G. 1957. Screening of microorganisms inhabiting apple leaf for their antibiotic properties against Venturia inaequalis (Cke.) Wint. Annu. Rep. Québec Soc. Prot. Plants 39:392-396.

42. Smith, F. D., Parker, D. M., and Köller, W. 1991. Sensitivity distribution of Venturia inaequalis to the sterol demethylation inhibitor flusilazole: Baseline sensitivity and implications for resistance monitoring. Phytopathology 81:392-396.

43. Sutton, D. K. 1992. A potential role for orchard sanitation in the management of apple scab (Venturia inaequalis (CKE) Wint.). M.Sc. thesis. University of New Hampshire, Durham.

44. Turner, H. A., and Dowson, W. J. 1931. The date and duration of the winter spore discharge of black spot. Tasman. J. Agric. N.S. 23:124-128. 